\title{
Chemical-Vapor-Deposited Graphene as Charge Storage Layer in Flash Memory Device
}

\author{
W. J. Liu, L. Chen, P. Zhou, Q. Q. Sun, H. L. Lu, S. J. Ding, and David W. Zhang \\ State Key Laboratory of ASIC and System, School of Microelectronics, Fudan University, Shanghai 200433, China \\ Correspondence should be addressed to W. J. Liu; wjliu@fudan.edu.cn
}

Received 14 September 2015; Revised 24 December 2015; Accepted 27 December 2015

Academic Editor: Giuseppe Compagnini

Copyright (C) 2016 W. J. Liu et al. This is an open access article distributed under the Creative Commons Attribution License, which permits unrestricted use, distribution, and reproduction in any medium, provided the original work is properly cited.

\begin{abstract}
We demonstrated a flash memory device with chemical-vapor-deposited graphene as a charge trapping layer. It was found that the average RMS roughness of block oxide on graphene storage layer can be significantly reduced from $5.9 \mathrm{~nm}$ to $0.5 \mathrm{~nm}$ by inserting a seed metal layer, which was verified by AFM measurements. The memory window is $5.6 \mathrm{~V}$ for a dual sweep of $\pm 12 \mathrm{~V}$ at room temperature. Moreover, a reduced hysteresis at the low temperature was observed, indicative of water molecules or $-\mathrm{OH}$ groups between graphene and dielectric playing an important role in memory windows.
\end{abstract}

\section{Introduction}

Flash memory has been highly demanded for mobile phone, digital camera, communication system, and data storage owing to its small size, high density, and low power. However, lateral scaling in flash memory will increase the capacitive coupling between the adjacent floating gates [1]. This parasitic capacitive coupling between neighboring cells will induce a wide distribution of threshold voltage because of the cell-tocell interference, leading to a remarkable read-out error in circuits. In particular beyond the $12 \mathrm{~nm}$ node, the issue of cell-to-cell interference will become much more severe [2]. To address this problem, the floating gate thickness reduction is one possible way. For conventionally used poly-Si floating gates, its thickness can be reduced to several nanometers; however, it will bring a large ballistic current during program processes [3], causing significant reliability issues. On the other hand, the charge storage capability in floating gates will degrade because of reduced density of state of poly-Si under such continuous scaling along the thickness direction [4]. Although thin metal layer was proposed to replace poly-Si floating gate, there are many other issues introduced at high temperatures, such as diffusion of metal into the blocking and tunneling oxide layer, and metal induced dielectric crystallization [5-7].
Recently, graphene, a two-dimension single layer of carbon atoms with $s p^{2}$ hybridized structure, has emerged as a promising material for future electronic applications owing to its unique physical and electrical properties [8-13]. Because the interlayer spacing between two monolayer graphene sheets is $0.34 \mathrm{~nm}[8]$, then the thickness of multilayer (e.g., 4-8 layers) graphene is around $1.5-3 \mathrm{~nm}$, which may be implemented into flash memory for the thickness reduction in the floating gate. Note that its work function of $\sim 4.6 \mathrm{can}$ be stabilized when the number of graphene layers reaches 4 [14]. Moreover, its thermal stability $\left(>1000^{\circ} \mathrm{C}\right)$ vanishes the diffusion issues at high temperatures, offering the benefits to the integration of memory devices. There are additional advantages for multilayer graphene as a floating gate, for example, (1) being compatible with conventional planar CMOS process line; (2) suppression of the ballistic current along the thickness direction because of reduced conductivity between layers; (3) large DOS; and (4) high work function which can increase the capability for storage and long-term data retention $[5,15]$. It was reported that graphene layers can be utilized as not only a floating gate for conventional silicon MOS capacitors $[5,15]$ but also a novel channel material of transition metal dichalcogenide, for example, $\mathrm{MoS}_{2}$ [16], high-k stack or PZT based charge-trap memory [17-20], organic nonvolatile memory [21], and transparent 
flexible charge-trap memory [22]. A large hysteresis (memory window) of $\sim 6 \mathrm{~V}$ was observed under a low voltage program/erase process [15]. In addition, graphene oxide (GO) was also incorporated into TANOS as a trapping layer, while it suffers the reliability issues since the charge storage capability will significantly degrade at high temperatures [23].

In this work, we demonstrated a flash memory device with chemical-vapor-deposited graphene as a charge trapping layer. The fabricated devices exhibit an increased memory window as a dual sweep bias was enhanced. Interestingly, we also observed a reduced hysteresis at low temperature, indicative of $-\mathrm{OH}$ or water molecules between graphene and dielectric playing an important role in memory windows.

\section{Experimental Details}

Graphene layers were prepared by a chemical-vapordeposition (CVD) technique in a home-made tube furnace. An $850 \mathrm{~nm}$ thick $\mathrm{Cu}$ film was thermally evaporated on the mica substrate at $500^{\circ} \mathrm{C}$, where atomically flat surface of single crystal mica substrate was obtained by a tape cleaving [8]. To remove oxidized layer and contaminations on $\mathrm{Cu}$ surface, $\mathrm{Cu} / \mathrm{mica}$ substrates were annealed in $\mathrm{H}_{2} / \mathrm{Ar}$ gas ambient at $1000^{\circ} \mathrm{C}$ for half hours prior to the graphene growth [24]. Then graphene was grown on the $\mathrm{Cu} / \mathrm{mica}$ substrate by introducing $\mathrm{CH}_{4}$ in the tube at the same temperature and the pressure inside the tube was kept roughly at one atmosphere. Graphene size $(50 \mu \mathrm{m} \times 50 \mu \mathrm{m})$ was patterned by definition by lithography and followed by an $\mathrm{O}_{2}$-plasma etching. The $\mathrm{Cu}$ film on mica was dissolved in $\mathrm{HCl}$ aqueous solution. The schematic device structure, optical image of the fabricated device, and its fabrication processes are illustrated in Figures $1(\mathrm{a}), 1(\mathrm{~b})$, and $1(\mathrm{c})$, respectively.

The tunneling oxide was a thermally grown $5 \mathrm{~nm}$ thick $\mathrm{SiO}_{2}$. The thickness of the tunneling oxide is determined from both ellipsometer spectrometry and separate electrical $C-V$ measurements. Graphene was then transferred onto the $\mathrm{SiO}_{2}$ $(5 \mathrm{~nm}) / \mathrm{p}$-Si substrate using the polymethyl methacrylate(PMMA-) assisted transfer method [24]. Prior to the growth of the blocking oxide, a seed layer of $\mathrm{Al}$ was deposited onto graphene $/ \mathrm{SiO}_{2} / \mathrm{Si}$ and oxidized in the $\mathrm{O}_{2}$ ambient. A $20 \mathrm{~nm}$ thick $\mathrm{Al}_{2} \mathrm{O}_{3}$ was subsequently deposited by atomic-layer deposition (ALD), where $\mathrm{Al}_{2} \mathrm{O}_{3}$ was grown using trimethyl aluminum (TMA) and $\mathrm{H}_{2} \mathrm{O}$ as precursors at $200^{\circ} \mathrm{C}$. The relative dielectric constant of $\mathrm{Al}_{2} \mathrm{O}_{3}$ is extracted to be 7.5 from the control sample. Finally the top electrode was formed in turn by electron-beam lithography, thermal evaporation of $\mathrm{Au}$, and a lift-off process in acetone. The Raman characterization was carried out by an Ar laser unit of $488 \mathrm{~nm}$ excitation. The surface roughness (RMS) was analyzed by atomic force microscopy (AFM). The electrical $I-V$ and $C$ $V$ measurements were performed using a semiconductor (Agilent B1500A) device analyzer and a precise impedance analyzer (Agilent 4294A) with a $50 \mathrm{mV}$ AC amplitude at $100 \mathrm{KHz}$, respectively.

\section{Results and Discussion}

Figure 2(a) shows the optical image of as-transferred graphene film on $\mathrm{SiO}_{2} / \mathrm{Si}$ substrate. To better characterize
CVD graphene, a silicon substrate with $90 \mathrm{~nm} \mathrm{SiO}_{2}$ was used here for the best optical contrast. The surface coverage of as-transferred bilayer graphene is more than $50 \%$. Note that all the Raman spectra shown in this paper are calibrated using silicon peak at $520 \mathrm{~cm}^{-1}$. Figure 2(b) shows the typical Raman spectra of monolayer and bilayer CVD graphene. It can be clearly seen that there is a D band in the as-transferred CVD graphene. It is quite different from the pristine one mechanically exfoliated from bulky graphite, which only has two main characteristic peaks of $\mathrm{G}$ and $2 \mathrm{D}$. This infers that transfer process needs to be further improved for the high quality graphene on $\mathrm{SiO}_{2} / \mathrm{Si}$ substrate. Note that a sharp line width $\left(\sim 30 \mathrm{~cm}^{-1}\right)$ and a single Lorentzian lineshape in $2 \mathrm{D}$ band were also observed for bilayer CVD graphene. It is due to an ordered $\mathrm{AB}$ stacking, resulting in a week electronic coupling between graphene layers [25].

Owing to its inherent characteristic of no dangling bonds, the top gate dielectric is quite tough to be formed on graphene. In order to alleviate this issue, a seed layer of $\mathrm{Al}$ was deposited and oxidized into an $\mathrm{Al}_{2} \mathrm{O}_{3}$ layer. Figures 3(a) and 3(b) show the AFM images of an atomic-layer-deposited 100-cycle $\mathrm{Al}_{2} \mathrm{O}_{3}$ film on highly oriented pyrolytic graphite (HOPG) substrate without and with an Al seed layer, respectively. It was observed that a striped pattern of $\mathrm{Al}_{2} \mathrm{O}_{3}$ film was formed along grain boundaries and defects sites without an $\mathrm{Al}$ seed layer, while a fairly uniform $\mathrm{Al}_{2} \mathrm{O}_{3}$ surface was achieved on $\mathrm{HOPG}$ with an $\mathrm{Al}$ seed layer. This prominent difference in $\mathrm{Al}_{2} \mathrm{O}_{3}$ /HOPG lies in the chemical inertness of HOPG surface, thus leading to a deep cluster or nucleation of $\mathrm{Al}_{2} \mathrm{O}_{3}$ dielectric film preferentially in the sites of grain boundaries $[26,27]$. It is worthwhile to mention that, in contrast to the pristine graphene, the functionalized surface is prone to ALD growth of a uniform high-k dielectric film although the film quality still needs further improvement [28]. The surface roughness (RMS) of an atomic-layer-deposited 100cycle $\mathrm{Al}_{2} \mathrm{O}_{3}$ film on $\mathrm{HOPG}$ using various thickness of $\mathrm{Al}$ seed layer was summarized in Figure 3(c). Without an $\mathrm{Al}$ seed layer, its average RMS is as large as $\sim 5.9 \mathrm{~nm}$, while it decreases to $0.55 \mathrm{~nm}$ when a $0.2 \mathrm{mg} \mathrm{Al}$ metal $\left(\sim 1 \mathrm{~nm} \mathrm{Al}_{2} \mathrm{O}_{3}\right)$ target was evaporated for the seed layer. It was also found that the RMS roughness can be further reduced if the thickness of an $\mathrm{Al}$ seed layer increases, as shown in Figure 3(c).

Next, we turn to the $C-V$ measurements of fabricated graphene flash memory cell with the help of an Al seed layer. Figure 4(a) shows the representative $C-V$ characteristics of fabricated graphene flash cell at room temperature. There is a clear hysteresis of $\sim 2.3 \mathrm{~V}$ under a dual sweep of $\pm 8 \mathrm{~V}$ for the $\mathrm{Au} / \mathrm{Al}_{2} \mathrm{O}_{3}$ /graphene/SiO$/ \mathrm{p}$-Si cell. For the control sample, almost no noticeable hysteresis was observed, as shown in the inset of Figure 4(a). The comparison of hysteresis for both graphene flash memory and control cell under various dual sweep biases is illustrated in Figure 4(b). It can be noticed that the memory window is $1.0 \mathrm{~V}, 2.3 \mathrm{~V}, 4.0 \mathrm{~V}$, and $5.6 \mathrm{~V}$ for the dual sweep of $\pm 6 \mathrm{~V}, \pm 8 \mathrm{~V}, \pm 10 \mathrm{~V}$, and $\pm 12 \mathrm{~V}$, respectively. The amount of charge storage in graphene layers can be estimated by $\Delta n=C_{\text {con }} \times \Delta V / q$, where $C_{\text {con }}$ is the unit control gate capacitance, that is, the capacitance of $\mathrm{Al}_{2} \mathrm{O}_{3}$ layer, $\Delta V$ is the memory window, and $q$ is the unit electron charge. As 


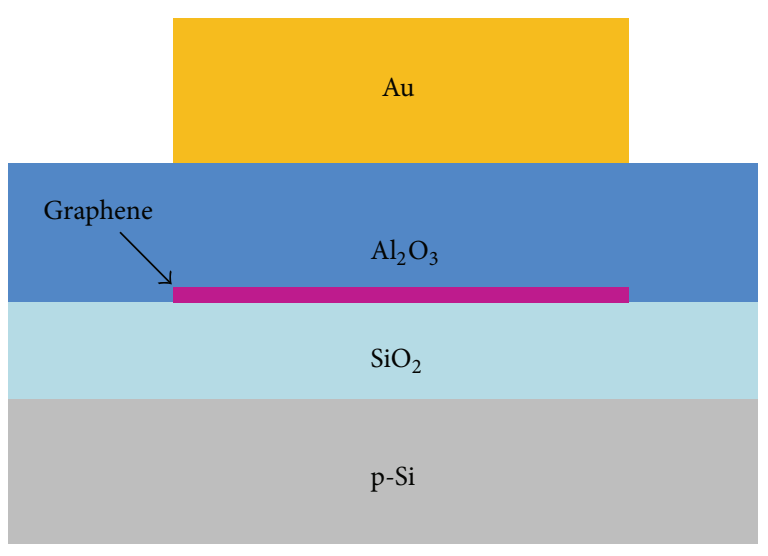

(a)

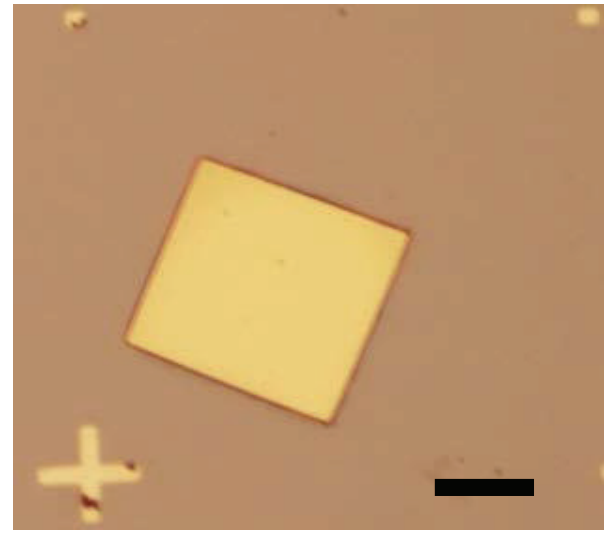

(b)

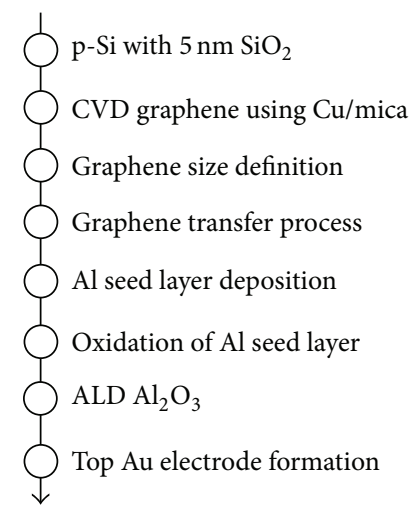

(c)

Figure 1: (a) The schematic of graphene flash memory cell $\left(\mathrm{Au} / \mathrm{Al}_{2} \mathrm{O}_{3} /\right.$ graphene/SiO$/ \mathrm{p}$ - $\left.\mathrm{Si}\right)$. (b) Top-view of fabricated graphene flash memory cell. The scale bar is $20 \mu \mathrm{m}$. (c) Process flow of fabricated graphene flash memory cell.

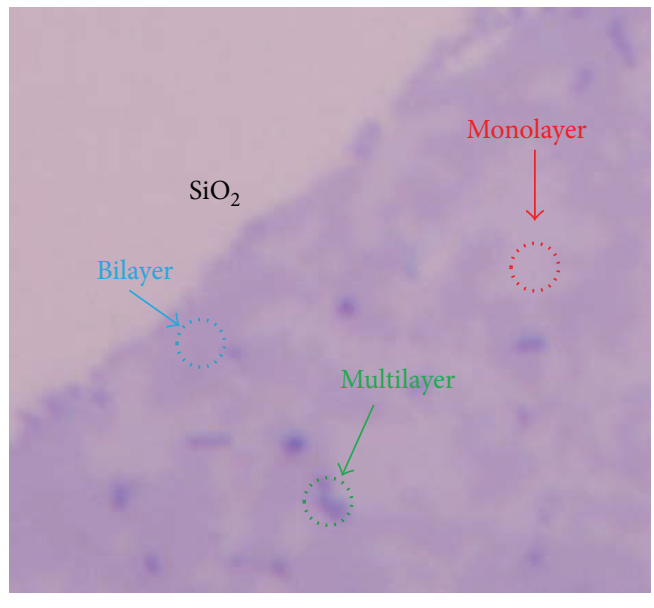

(a)

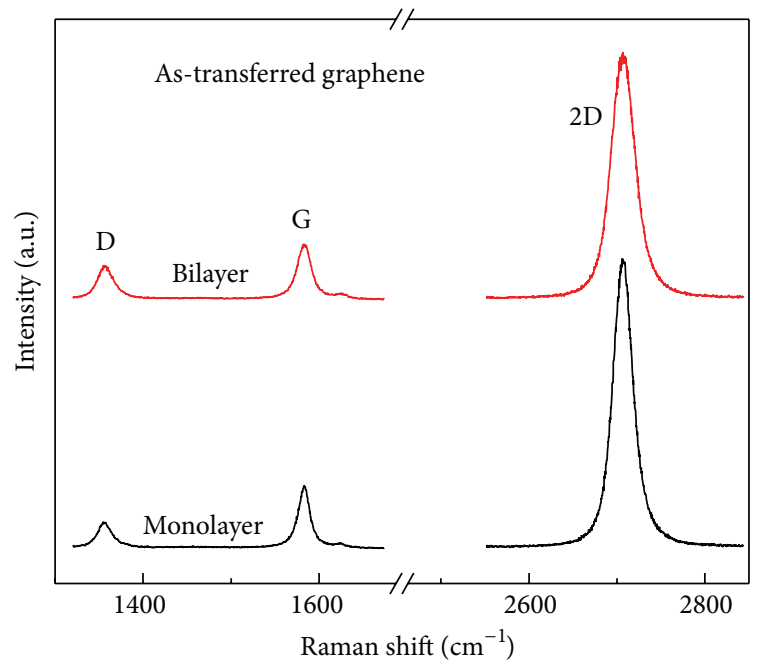

(b)

Figure 2: (a) The optical image of as-transferred CVD graphene on $\mathrm{SiO}_{2} / \mathrm{Si}$ substrate. The image size is $20 \mu \mathrm{m} \times 20 \mu \mathrm{m}$. (b) Raman spectra of as-transferred monolayer and bilayer graphene. 


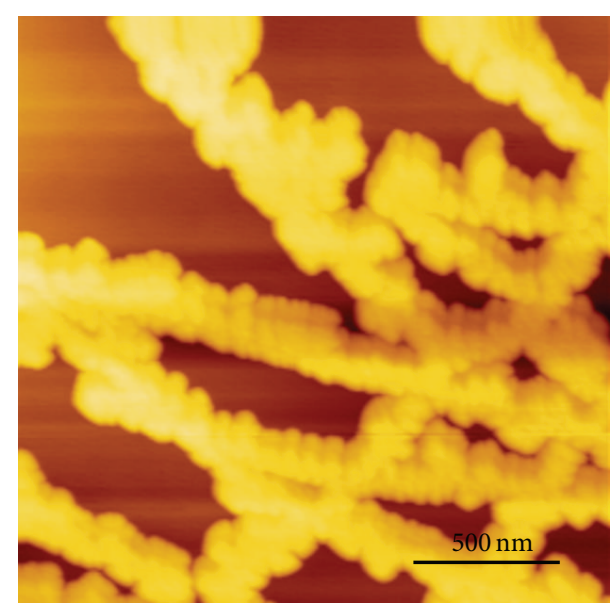

(a)

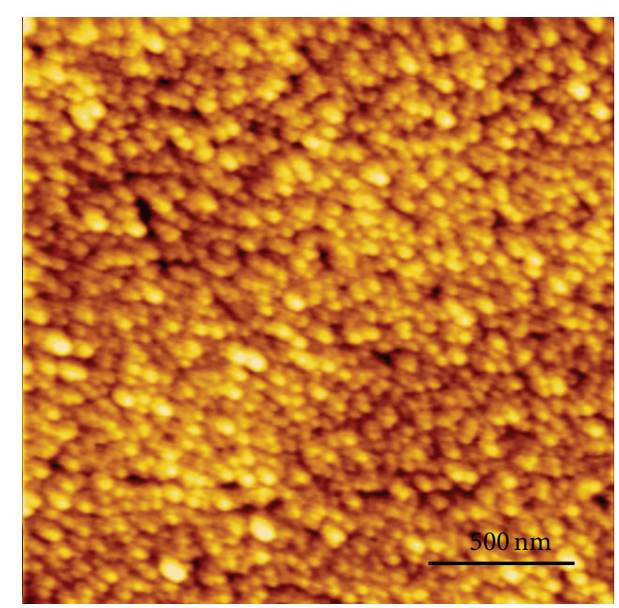

(b)

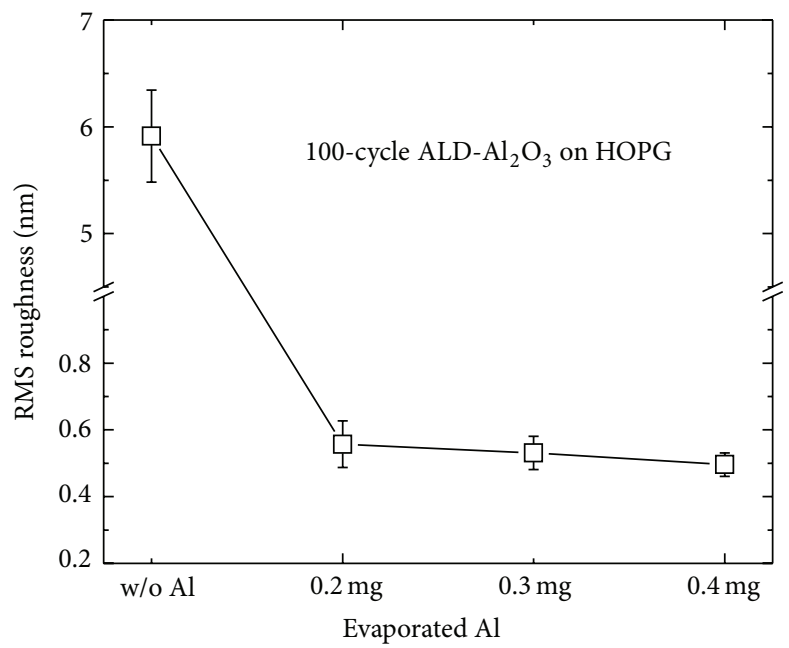

(c)

FIGURE 3: (a) Atomic force microscopy (AFM) image of an atomic-layer-deposited 100-cycle $\mathrm{Al}_{2} \mathrm{O}_{3}$ film on highly oriented pyrolytic graphite (HOPG) substrate without and with an Al seed layer. The scale bar is $500 \mathrm{~nm}$. (b) Surface roughness (RMS) of an atomic-layer-deposited 100-cycle $\mathrm{Al}_{2} \mathrm{O}_{3}$ film on HOPG without and with $0.2 \mathrm{mg}, 0.3 \mathrm{mg}$, and $0.4 \mathrm{mg} \mathrm{Al}$ for the seed layer thermal evaporation.

a result, the storage charge density in graphene layer for the hysteresis of $\sim 2.3 \mathrm{~V}$ in Figure 4(a) is accordingly around $4.76 \times$ $10^{12} \mathrm{~cm}^{-2}$. In contrast to graphene flash memory cell, only a small hysteresis of $\sim 40 \mathrm{mV}$ at the dual sweep of $\pm 12 \mathrm{~V}$ remains for the control cell at room temperature; see Figure 4(b). This indicates a pronounced memory window in graphene flash memory cell, where the memory effect results from the charge storage in graphene film, consistent with the previous reports $[7,15]$. Compared to monolayer and bilayer graphene, a significant hysteresis may take place in few layer graphene based flash memory because of its large density of state [15]. The process improvement of the growth of multilayer graphene is further needed to realize large memory windows.

We also examined the $C-V$ characteristics of graphene flash cells at low temperature of $250 \mathrm{~K}$. It is interesting that the memory window for graphene flash memory cell decreases significantly, as shown in Figure 4(b), that is, even only a small hysteresis of $1.5 \mathrm{~V}$ for a dual sweep of $\pm 12 \mathrm{~V}$.
Similar hysteretic behaviors have also been observed in the $I_{d}-V_{g}$ behaviors for a dual sweep $V_{g}$ in the back-gated graphene field-effect transistor [29], and Dirac point shift in a quantum capacitance measurement [30]. This reduction in the hysteresis in graphene or carbon nanotube field-effect transistors was attributed to the orientation polarization of water [29-36]. Hydroxyl groups $(-\mathrm{OH})$ can couple to the dangling bonds of $\mathrm{Si}$ and build up a layer of silanol $(\mathrm{SiOH})$ groups, which is very hydrophilic [37, 38]. Water molecules can easily attach to the $\mathrm{SiOH}$ and contribute to the charge transfer [36]. It was reported that the formation of $\mathrm{Si}-\mathrm{O}-\mathrm{Si}$ siloxane from the hydration of silanol groups will take place at more than $450^{\circ} \mathrm{C}$ [39]. In case of our transfer process, water molecules bonding to $\mathrm{Si}-\mathrm{OH}$ silanol groups will thus inevitably be introduced in the interfaces between graphene and dielectrics (e.g., $\mathrm{SiO}_{2}$ ). The fact that the hysteresis reduces significantly at low temperatures indicates there is a clear mechanism difference in electron trapping in graphene flash 


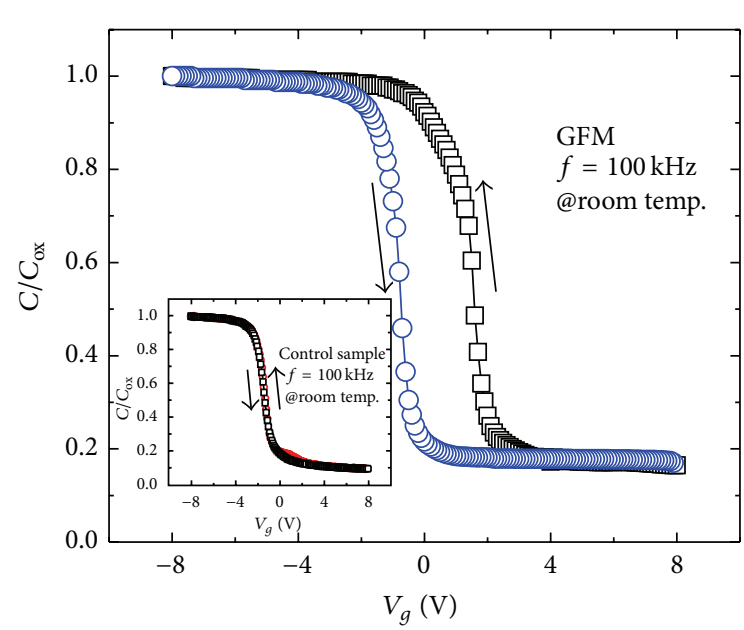

(a)

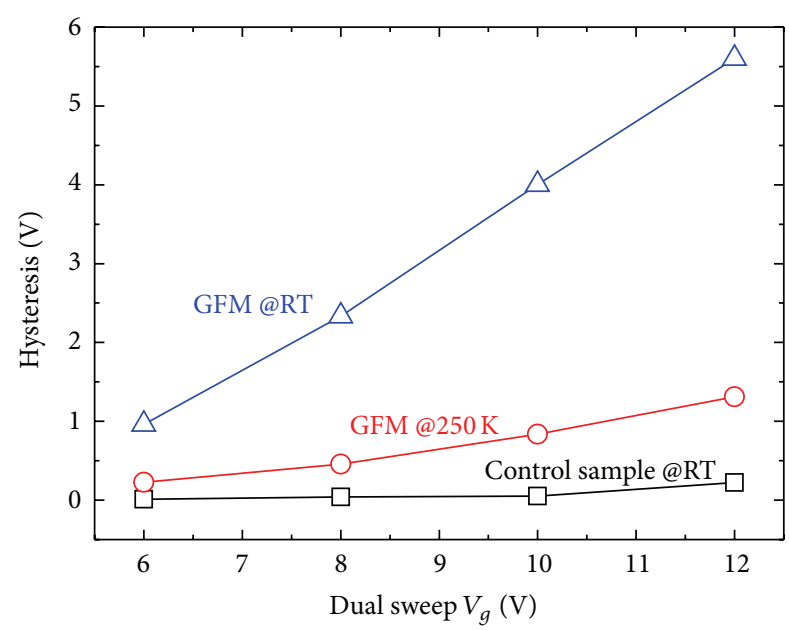

(b)

FIGURE 4: (a) Representative capacitance-voltage $(C-V)$ characteristics of fabricated graphene flash memory at room temperature (RT). Inset shows $C-V$ characteristics of the control sample. The arrows denote the sweep directions. (b) Comparison of hysteresis of graphene flash memory cell and control sample at both RT and $250 \mathrm{~K}$.

cell. Thus, it is believed that the orientation polarization of water molecules plays a crucial role in the memory window for graphene memory devices at the low temperature.

\section{Conclusion}

In summary, a flash memory device with chemical-vapordeposited graphene as a charge trapping layer was fabricated. A buffer $\mathrm{Al}_{2} \mathrm{O}_{3}$ layer oxidized from a seed layer can reduce one order of magnitude of the average RMS roughness, prior to the growth of $\mathrm{ALD} \mathrm{Al}_{2} \mathrm{O}_{3}$ blocking oxide, which is important to achieve high performance graphene memory devices. In addition, large memory window of $5.6 \mathrm{~V}$ was observed for a dual sweep of $\pm 12 \mathrm{~V}$ at room temperature. It exhibits a remarkable reduction in memory window at the low temperature, which is attributed to the decrease of water polarization.

\section{Conflict of Interests}

The authors declare that there is no conflict of interests regarding the publication of this paper.

\section{Acknowledgments}

This work was supported in part by the Japan Society for the Promotion of Science (JSPS) and the Startup Project JJH1233103 at Fudan University in China. W. J. Liu would like to thank Professor A. Toriumi and K. Nagashio for their valuable comments and suggestions.

\section{References}

[1] J.-D. Lee, S.-H. Hur, and J.-D. Choi, "Effects of floating-gate interference on NAND flash memory cell operation," IEEE Electron Device Letters, vol. 23, no. 5, pp. 264-266, 2002.
[2] W. Cao, J. H. Kang, S. Bertolazzi, A. Kis, and K. Banerjee, "Can 2D-nanocrystals extend the lifetime of floating-gate transistor based nonvolatile memory?" IEEE Transactions on Electron Devices, vol. 61, no. 10, pp. 3456-3464, 2014.

[3] S. Raghunathan, T. Krishnamohan, K. Parat, and K. Saraswat, "Investigation of ballistic current in scaled floating-gate NAND FLASH and a solution," in Proceedings of the International Electron Devices Meeting (IEDM '09), pp. 1-4, Baltimore, Md, USA, December 2009.

[4] S. Jayanti, X. Yang, R. Suri, and V. Misra, "Ultimate scalability of TaN metal floating gate with incorporation of high- $k$ blocking dielectrics for flash memory applications," in Proceedings of the IEEE International Electron Devices Meeting (IEDM '10), pp. 5.3.1-5.3.4, San Francisco, Calif, USA, December 2010.

[5] A. Misra, H. Kalita, M. Waikar et al., "Multilayer graphene as charge storage layer in floating gate flash memory," in Proceedings of the 4th IEEE International Memory Workshop (IMW '12), pp. 1-4, Milan, Italy, May 2012.

[6] P. K. Singh, K. K. Singh, R. Hofmann, K. Armstrong, N. Krishna, and S. Mahapatra, "Au nanocrystal flash memory reliability and failure analysis," in Proceedings of the 15th IEEE International Symposium on the Physical and Failure Analysis of Integrated Circuits (IPFA '08), pp. 1-5, IEEE, Singapore, July 2008.

[7] S. Jayanti, X. Yang, and V. Misra, "Investigation of thermal stability of high- $k$ interpoly dielectrics in TaN metal floating gate memory structures," in Proceedings of the 3rd IEEE International Memory Workshop (IMW '11), pp. 1-4, Monterey, Calif, USA, May 2011.

[8] K. S. Novoselov, A. K. Geim, S. V. Morozov et al., "Electric field effect in atomically thin carbon films," Science, vol. 306, no. 5696, pp. 666-669, 2004.

[9] A. K. Geim and K. S. Novoselov, "The rise of graphene," Nature Materials, vol. 6, no. 3, pp. 183-191, 2007.

[10] Y. Zhang, Y.-W. Tan, H. L. Stormer, and P. Kim, "Experimental observation of the quantum Hall effect and Berry's phase in graphene," Nature, vol. 438, no. 7065, pp. 201-204, 2005. 
[11] Y.-M. Lin, C. Dimitrakopoulos, K. A. Jenkins et al., "100 GHz transistors from wafer-scale epitaxial graphene," Science, vol. 327, no. 5966, article 662, 2010.

[12] F. Schwierz, "Graphene transistors," Nature Nanotechnology, vol. 5, no. 7, pp. 487-496, 2010.

[13] F. Schedin, A. K. Geim, S. V. Morozov et al., "Detection of individual gas molecules adsorbed on graphene," Nature Materials, vol. 6, no. 9, pp. 652-655, 2007.

[14] H. Hibino, H. Kageshima, M. Kotsugi, F. Maeda, F.-Z. Guo, and Y. Watanabe, "Dependence of electronic properties of epitaxial few-layer graphene on the number of layers investigated by photoelectron emission microscopy," Physical Review B, vol. 79, no. 12, Article ID 125437, 2009.

[15] A. J. Hong, E. B. Song, H. S. Yu et al., "Graphene flash memory," ACS Nano, vol. 5, no. 10, pp. 7812-7817, 2011.

[16] S. Bertolazzi, D. Krasnozhon, and A. Kis, "Nonvolatile memory cells based on $\mathrm{MoS}_{2}$ /graphene heterostructures," ACS Nano, vol. 7, no. 4, pp. 3246-3252, 2013.

[17] N. Zhan, M. Olmedo, G. P. Wang, and J. L. Liu, "Graphene based nickel nanocrystal flash memory," Applied Physics Letters, vol. 99, no. 11, Article ID 113112, 2011.

[18] S. Lee, E. B. Song, S. Kim et al., "Impact of gate work-function on memory characteristics in $\mathrm{Al}_{2} \mathrm{O}_{3} / \mathrm{HfOx} / \mathrm{Al}_{2} \mathrm{O}_{3}$ /graphene charge-trap memory devices," Applied Physics Letters, vol. 100, no. 2, Article ID 023109, 2012.

[19] S. A. Imam, T. Deshpande, A. Guermoune, M. Siaj, and T. Szkopek, "Charge transfer hysteresis in graphene dual-dielectric memory cell structures," Applied Physics Letters, vol. 99, no. 8, Article ID 082109, 2011.

[20] E. B. Song, B. Lian, S. Min Kim et al., "Robust bi-stable memory operation in single-layer graphene ferroelectric memory," Applied Physics Letters, vol. 99, no. 4, Article ID 042109, 2011.

[21] Y. S. Ji, M. Choe, B. J. Cho et al., "Organic nonvolatile memory devices with charge trapping multilayer graphene film," Nanotechnology, vol. 23, no. 10, Article ID 105202, 2012.

[22] S. M. Kim, E. B. Song, S. Lee et al., "Transparent and flexible graphene charge-trap memory," ACS Nano, vol. 6, no. 9, pp. 7879-7884, 2012.

[23] S. Wang, J. Pu, D. S. H. Chan, B. J. Cho, and K. P. Loh, "Wide memory window in graphene oxide charge storage nodes," Applied Physics Letters, vol. 96, no. 14, Article ID 143109, 2010.

[24] J. L. Qi, K. Nagashio, T. Nishimura, and A. Toriumi, “The crystal orientation relation and macroscopic surface roughness in hetero-epitaxial graphene grown on $\mathrm{Cu} / \mathrm{mica}$, Nanotechnology, vol. 25, no. 18, Article ID 185602, 2014.

[25] A. Reina, X. Jia, J. Ho et al., "Large area, few-layer graphene films on arbitrary substrates by chemical vapor deposition," Nano Letters, vol. 9, no. 1, pp. 30-35, 2009.

[26] N. Takahashi, K. Watanabe, T. Taniguchi, and K. Nagashio, "Direct deposition of high- $k \mathrm{Y}_{2} \mathrm{O}_{3}$ on $h$-BN by atomic layer deposition," in Proceedings of the International Conference on Solid-state Devices and Materials (SSDM '14), p. 1076, Ibaraki, Japan, September 2014.

[27] N. Takahashi, T. Taniguchi, K. Watanabe, and K. Nagashioi, "Atomic layer deposition of $\mathrm{Y}_{2} \mathrm{O}_{3}$ on $h$ - $\mathrm{BN}$ for a gate stack in graphene FETs," Nanotechnology, vol. 26, no. 17, Article ID 175708, 2015.

[28] P. Zhou, S. B. Yang, Q. Q. Sun et al., "Direct deposition of uniform high- $\kappa$ dielectrics on graphene," Scientific Reports, vol. 4, article 6448, 2014.
[29] W. J. Liu, X. W. Sun, X. A. Tran et al., "Observation of the ambient effect in BTI characteristics of back-gated single layer graphene field effect transistors," IEEE Transactions on Electron Devices, vol. 60, no. 8, pp. 2682-2686, 2013.

[30] K. Nagashio, T. Nishimura, and A. Toriumi, "Estimation of residual carrier density near the Dirac point in graphene through quantum capacitance measurement," Applied Physics Letters, vol. 102, no. 17, Article ID 173507, 2013.

[31] P. L. Levesque, S. S. Sabri, C. M. Aguirre et al., "Probing charge transfer at surfaces using graphene transistors," Nano Letters, vol. 11, no. 1, pp. 132-137, 2011.

[32] S. Ryu, L. Liu, S. Berciaud et al., "Atmospheric oxygen binding and hole doping in deformed graphene on a $\mathrm{SiO}_{2}$ substrate," Nano Letters, vol. 10, no. 12, pp. 4944-4951, 2010.

[33] W. Kim, A. Javey, O. Vermesh, Q. Wang, Y. Li, and H. Dai, "Hysteresis caused by water molecules in carbon nanotube field-effect transistors," Nano Letters, vol. 3, no. 2, pp. 193-198, 2003.

[34] T. Lohmann, K. Von Klitzing, and J. H. Smet, "Four-terminal magneto-transport in graphene $\mathrm{p}-\mathrm{n}$ junctions created by spatially selective doping," Nano Letters, vol. 9, no. 5, pp. 1973-1979, 2009.

[35] K. Nagashio, T. Yamashita, T. Nishimura, K. Kita, and A. Toriumi, "Electrical transport properties of graphene on $\mathrm{SiO}_{2}$ with specific surface structures," Journal of Applied Physics, vol. 110, no. 2, Article ID 024513, 2011.

[36] M. Lafkioti, B. Krauss, T. Lohmann et al., "Graphene on a hydrophobic substrate: doping reduction and hysteresis suppression under ambient conditions," Nano Letters, vol. 10, no. 4, pp. 1149-1153, 2010.

[37] D. B. Asay and S. H. Kim, "Evolution of the adsorbed water layer structure on silicon oxide at room temperature," The Journal of Physical Chemistry B, vol. 109, no. 35, pp. 16760-16763, 2005.

[38] D. B. Asay, A. L. Barnette, and S. H. Kim, "Effects of surface chemistry on structure and thermodynamics of water layers at solid-vapor interfaces," The Journal of Physical Chemistry C, vol. 113, no. 6, pp. 2128-2133, 2009.

[39] N. Hirashita, S. Tokitoh, and H. Uchida, "Thermal desorption and infrared studies of plasma-enhanced chemical vapor deposited $\mathrm{SiO}$ films with tetraethylorthosilicate," Japanese Journal of Applied Physics, vol. 32, no. 4, part 1, p. 1787, 1993. 

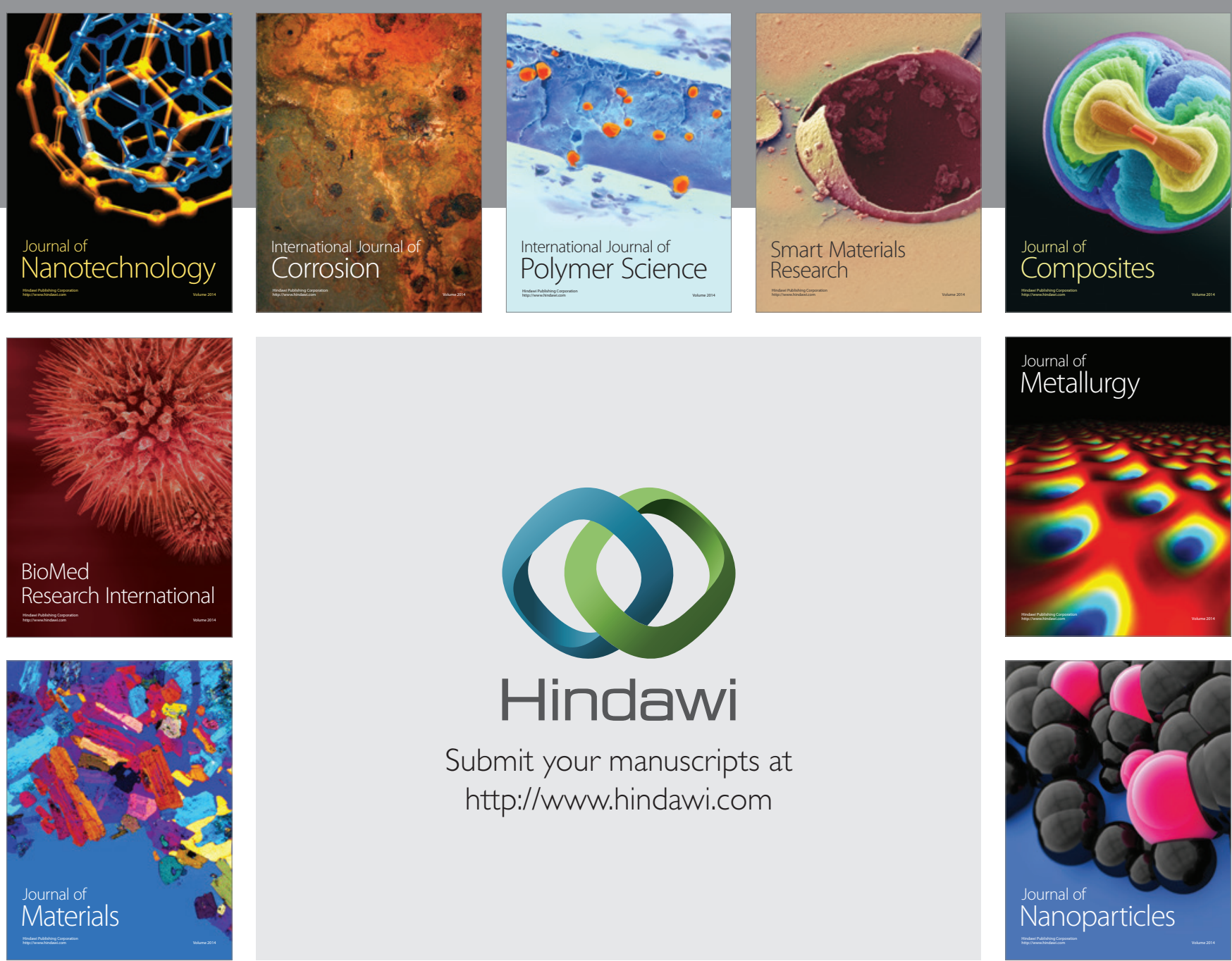

\section{Hindawi}

Submit your manuscripts at

http://www.hindawi.com

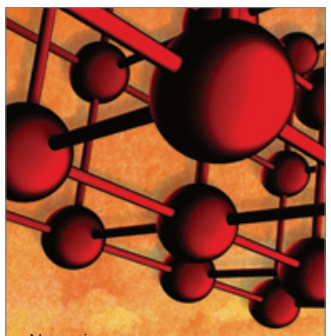

Materials Science and Engineering
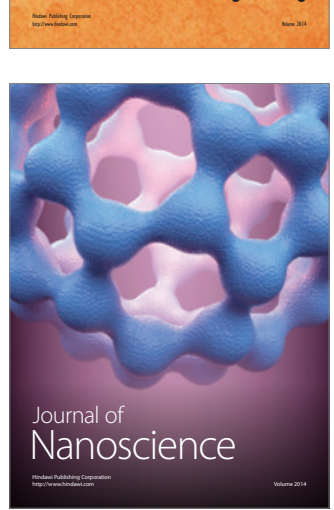
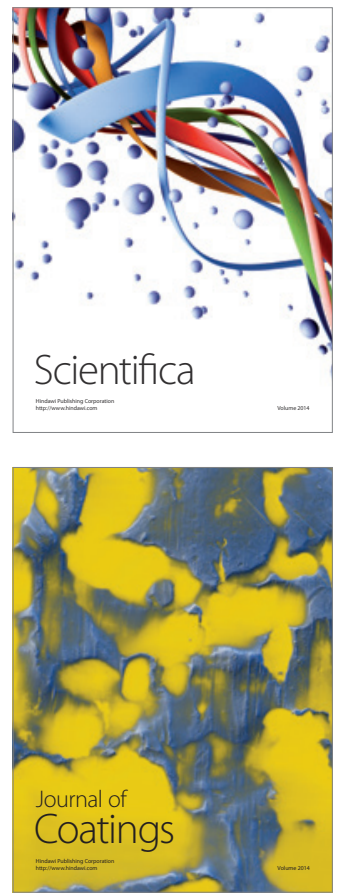
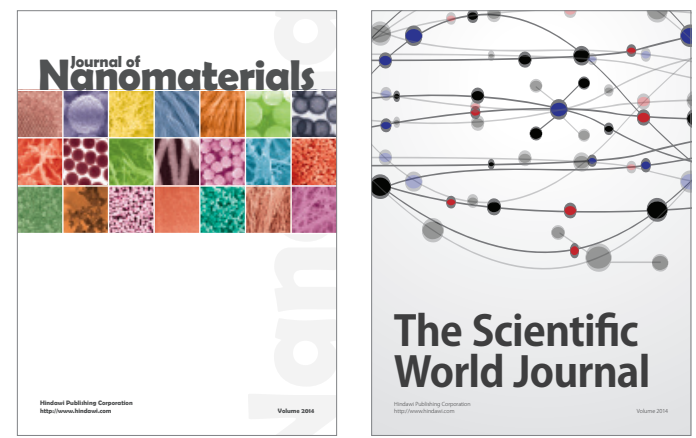

The Scientific World Journal
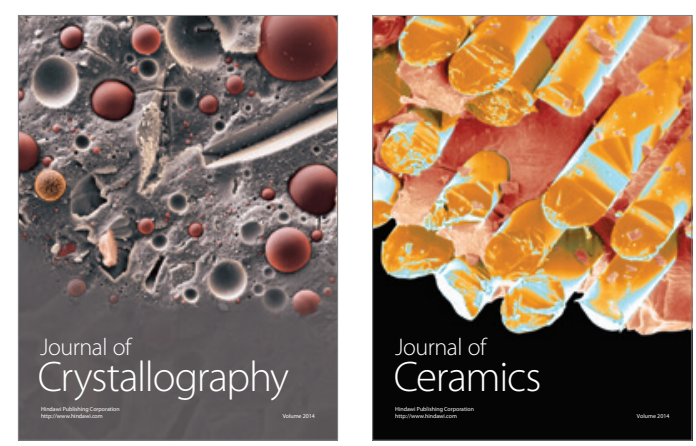
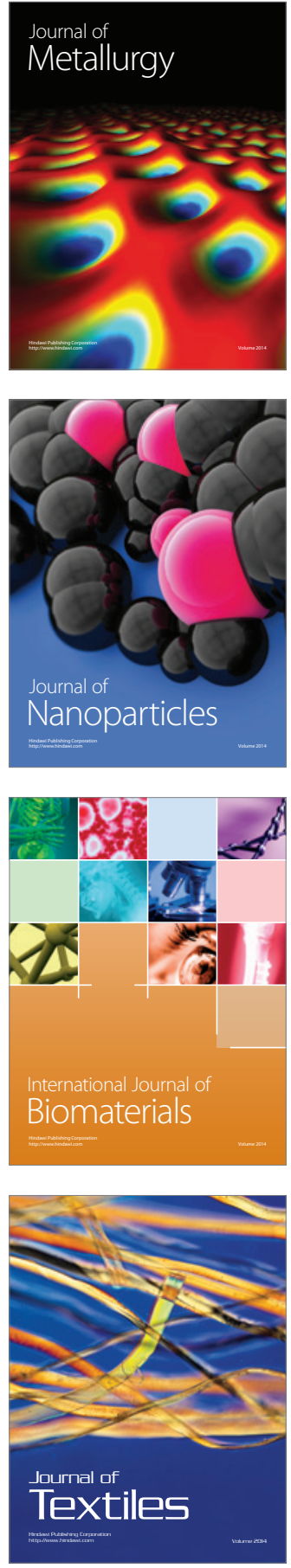